\title{
Pierre Bourdieu: os mandamentos do infelectual
}

Juremir Machado da Silva

Dr. em Sociologia - Univ. René Descartes, Paris V, Sorbonne
ENDEUSADO OU DETESTADO, a ponto de ser chamado por seus detratores de Bourdivin, o sociólogo Pierre Bourdieu, 68, professor no célebre e prestigioso Collège de France, reina, para muitos dos seus admiradores, como o último dos maîtres à penser no país do intelectual engajado Jean-Paul Sartre, cujo espectro continua a rondar o imaginário dos pensadores críticos, dos utopistas de esquerda, dos nostálgicos da revolução proletária, dos adversários do neoliberalismo e mesmo dos ressentidos por razões diversas.

Defensor do caráter científico da sociologia, adversário do ensaísmo e inimigo dos "intelectuais da mídia", Bourdieu, nos últimos anos em luta contra o neoliberalismo, assumiu posições cada vez mais à esquerda, chegando a ser rotulado de demagogo e de populista por alguns dos seus principais oponentes. Crítico implacável dos privilégios garantidos e transmitidos por instituições, é autor de alguns dos livros sociológicos mais polêmicos dos últimos 40 anos, entre os quais Os Herdeiros: os estudantes e a cultura (1964), A Reprodução: elementos de uma teoria do sistema de ensino, com JeanClaude Passeron (1970), A Distinção: crítica social do juízo (1979), Homo academicus (1984), A Nobreza de Estado: Grandes Escolas e espírito de corpo (1989), As Regras da arte: gênese e estrutura do campo literário (1992), Sobre a televisão (1996) e A Dominação masculina (1998).

Diretor da revista Actes de la recherche en sciences sociales, uma das publicações acadêmicas mais respeitadas do mundo, e criador da editora Liber Raisons d'Agir, cujos pequenos livros, em forma de panfletos contundentes, vendem em média 300 mil exemplares, Pierre Bourdieu não teme atacar as instituições que lhe dão trabalho e distinção social. Assim, desmontou os mecanismos elitistas e corporativos das principais instâncias de poder no mundo contemporâneo: educação, cultura, posi- 
ção na esfera estatal e mídia. Além disso, a apropriação da cultura como símbolo de distinção é um dos seus temas favoritos através do qual pulveriza os modismos, o esnobismo e o vazio das elites de plantão. Quanto mais bate nos deslumbrados e nos afetados, mais é adorado por estes, que encontram nele o último baluarte do purismo intelectual em oposição à vulgaridade da indústria cultural.

Criador ou disseminador de conceitos como "campo" ou "habitus", Pierre Bourdieu vê os homens em luta permanente pelo prestígio e pela ascensão social. Segundo o crítico literário Jean-Marc Biasi, o homem, para Bourdieu, não é o lobo do homem, mas o cão. Em meio a tanta controvérsia, o pensador avança e não sem razões. Ele sabe e denuncia que um escritor se define, hoje, mais pelo seu lugar na mídia do que pelo valor da sua obra. Nada que possa surpreender os brasileiros. Glória efêmera, talvez, mas não menos rentável. O campo cultural aparece como uma espécie de farsa onde cada ator representa o papel que gostaria de encarnar na realidade. O consumidor, porém, já não consegue separar a ficção do real e aceita a encenação como verdade.

Nesta entrevista, Pierre Bourdieu retoma o percurso do combatente: revisita e desmantela as estratégias de poder que sempre se apresentam como naturais e necessárias. Nada do que é humano lhe é natural. Poupado no já célebre "caso Sokal", Bourdieu faz o balanço do pensamento francês neste final de milênio. Itinerário de um serial-killer das idéias.

Revista FAMEcOS: $O$ senhor é considerado como o "intelectual mais poderoso da França", conforme a recente manchete de capa da revista L'Evénement du jeudi, e, segundo outros, como o sociólogo mais importante do mundo. Numa época em que para muitos as ciências sociais estão em crise, o caráter científico da sociologia parece-lhe inegável. Pode-se realmente demonstrar essa cientificidade?

Pierre Bourdieu: Quero deter-me, antes de tudo, no conteúdo da questão. Que significa "intelectual mais poderoso da França"? Com certeza, estamos no terreno do poder. Mas de qual poder? O poder universitário, tal qual o analiso no Homo academicus? Nesse caso, é fácil constatar que pertencer ao Collège de France, onde, à época do meu estudo, se encontravam gente como Dumézil, Lévi-Strauss, Braudel ou Foucault, não garante praticamente nenhuma espécie de poder propriamente universitário. Entendo por isso um poder sobre as instâncias de reprodução do corpo docente e mesmo científico. Os "heréticos consagrados", como eu os designava, são mais ou menos excluídos, apesar do prestígio, dessa forma de poder. E, sem dúvida, isso é uma pena para a qualidade da vida científica e para os jovens pesquisadores qualificados que nela querem se engajar.

Falar de poder sobre as instâncias de difusão, e em particular na mídia, pertencer ao Collège de France, pelo prestígio que isso confere, pode dar certa autoridade junto a editores e jornalistas. Acho, por exemplo, que meu amigo Michel Foucault tinha um "poder" desse tipo. Mas esse poder baseado no prestígio é pouca coisa quando comparado ao que têm certos intelectuais da mídia, ligados por laços orgânicos aos meios da imprensa e da edição. As Edições Grasset, na França, por exemplo, através dos livros publicados ou suscitados e dos órgãos de imprensa controlados por vias diversas, L'Evénement du jeudi, Le Point, Le Magazine littéraire, podem, como se vê atualmente nas campanhas difamatórias sustentadas contra mim, tentar fazer triunfar os interesses dos intelectuais da mídia, cujo papel analisei em Sobre a televisão.

Os detentores desse poder característico da mídia, assim como os detentores do poder propriamente universitário, podem não ter nenhum pouco disso que se chama ordinariamente de prestígio, isso que aparece quando se fala do "sociólogo mais importante do mundo", ou seja, o sociólogo que mais interessa aos sociólogos em todo o mundo. As duas espécies de poder que evoco, universitário ou de mídia, caracterizam-se primeiramente por ser nacionais, isto 
é, reduzidos aos limites da nação, francesa, no caso, e da língua nacional. Por isso, para medir o "prestígio" ou, mais precisamente, o capital simbólico dos pesquisadores estudados no Homo academicus, considerei as traduções em língua estrangeira, o número de menções no Citation Index e em outros índices de reconhecimento internacional. Desse ponto de vista, os meus "heréticos consagrados" distinguiam-se com clareza dos universitária ou midiaticamente poderosos.

Posso agora voltar à questão da cientificidade das ciências sociais e, particularmente, da sociologia. Devo salientar, antes de tudo, que a sociologia tem o triste privilégio de ser a única disciplina para a qual essa pergunta nunca pára de ser posta, quando, em realidade, ela nada tem a invejar, bem ao contrário, das outras ciências sociais; nem quanto aos métodos, modelização, uso da estatística, técnicas de coleta de dados, nem quanto ao conceitos e teorias, especialmente a etnologia e a história. A comparação com a economia exigiria uma análise mais complexa. Penso, de fato, que a sociologia é uma ciência cumulativa e nunca tive nenhuma pretensão à originalidade absoluta reivindicada, a meu ver de maneira bastante ingênua, por certos filósofos contemporâneos, principalmente os que são classificados com freqüência na categoria dos "pós-modernos". Sempre tentei integrar, sem dúvida ao custo de grandes esforços, as aquisições de tendências tradicionalmente consideradas como antagônicas; além disso, a sociologia possui um instrumental teórico ao mesmo tempo mais complexo, mais unificado e mais ajustado ao real do que o das demais ciências sociais, inclusive a economia.
RF: Professor no Collège de France e intelectual reconhecido internacionalmente, todos os tipos de conformismo continuam a ser os seus objetos de ataque. O senhor seria, como querem alguns dos seus detratores, um novo Sartre?

Bourdieu: Não tenho nem a pretensão nem o desejo de encarnar a figura do intelectual total realizada por Sartre. Dito isso, penso que a minha singularidade no campo intelectual francês, e a fortiori mundial, onde essa figura, apesar de algumas exceções, entre as quais Chomsky, nunca teve alta cotação, por razões que se pode compreender historicamente, reside na minha vontade de defender a função histórica do intelectual. Tal qual ela foi inventada na França com Émile Zola e o caso Dreyfus e perpetuada desedéchentão até Sartre e a luta dos intelectuais contra a tortura na Argélia. Ou seja, a idéia de que o intelectual se define como aquele que, apoiado num capital de reconhecimento e de competência, adquirido no campo literário ou filosófico, como Zola, Gide ou Sartre, ou no campo científico, como Chomsky, hoje, ou baseado nos valores correntes nesses universos, como a verdade, intervém de forma pontual no campo político, sem se converter em político.

Essa definição de intelectual nada tem de anódino e, entre todas as boas razões que os intelectuais da mídia, isto é, os "intelectuais" feitos por e para a mídia, têm para me detestar, a mais evidente é, sem dúvida, a minha obstinação em lembrá-los disso. Sartre não acumulou o seu capital simbólico assinando petições, conduzindo manifestações ou vendendo o Libération na rua, menos ainda aparecendo na televisão, mas escrevendo romances, peças de teatro e obras filosóficas. Não é por uma forma qualquer de conservadorismo aristocrático que acho necessário defender a antiga de- 
finição de intelectual. A competência específica e o capital simbólico adquiridos num campo autônomo representam a condição de autonomia dos intelectuais em relação aos poderes, especialmente políticos. Trata-se da capacidade deles de resistir ao conformismo e a todas as formas de dependência e de servilismo, como as do comentarista, sob retribuição, da vida política, ou do expert disposto a justificar qualquer política, ou a do animador frívolo, tipicamente francês, que, sob a cobertura da leveza, da elegância e da liberdade transgressora, ratifica ou aceita a ordem do mundo como ela é.

RF: Com o caso Sokal se anunciou por toda parte a decadência do pensamento francês e de certas imposturas atribuídas a ele. É o pensamento francês que está em crise ou certa idéia da vida intelectual e do papel dos maîtres à penser?

Bourdieu: Não sou um incondicional do pensamento francês, sobretudo nos aspectos paródicos que Sokal e Bricmont, com razão, denunciaram; os quais desabrocharam em certas formas de cultural studies. Dito isso, para além das imposturas e das aproximações pretensiosas do falso radicalismo, que alguns franceses, como Jacques Bouveresse, já tinham submetido, desde muito tempo, à crítica, existem também na filosofia francesa dos anos 70 e especialmente em Gilles Deleuze e Michel Foucault, inovações teóricas e conquistas intelectuais de primeira grandeza, ligadas, sem dúvida, à preocupação de desempenhar o papel de intelectual à antiga. Essas inovações e essas conquistas, condenadas pelos pequenos ensaístas conservadores sob o nome de "pensamento 68", merecem, assim como o espírito de subversão que lhes serve de princípio, ser defendidas contra o retorno à falsa neutralidade ética do expert ou do scholar, simples máscara da submissão à ordem estabelecida.

RF: Os intelectuais traíram novamente a vocação crítica que deve caracterizá-los ao aceitar como verdade os cânticos da ideologia neoliberal?

Bourdieu: Creio que, por preguiça intelectual, mas também sob o efeito do desencantamento ligado à melhoria das condições de existência das profissões intelectuais - com os tours de conferências e os rendosos cursos nos Estados Unidos, mais a colaboração regular com jornais ou hebdomadários - ou à queda do movimento "comunista" internacional e nacional, os intelectuais, pouco a pouco, renderam-se à visão neoliberal. Com freqüência, de maneira tão mais radical e total quanto maior era a adesão à mitologia "comunista". Entre os fatores que determinaram essa conversão coletiva de boa parte dos intelectuais franceses, embora a maioria dos países europeus tenha sofrido evolução análoga, não se pode esquecer a ação deliberada e organizada de um certo número de indivíduos e de instituições, think tanks organizados e financiados pelas grandes fundações americanas, revistas, colóquios, seminários, etc. O livrinho de Keith Dixon, Os Evangelistas do mercado, que vamos publicar na coleção "Razões de agir", descreve bem esse processo no caso da Inglaterra. Mas tivemos o equivalente disso na França com o Congresso para a liberdade da cultura, com a revista Preuves e com Raymond Aron. Seria necessário realizar uma pesquisa semelhante quanto à América Latina e, em especial, ao Brasil. Em geral, seria preciso descrever sociologicamente as vias, com freqüência tortuosas e dissimuladas, tomadas pelo imperialismo propriamente cultural. Apresentei, com Loïc Wacquant, um primeiro esboço de tal análise num artigo intitulado "Sobre as astúcias da razão imperialista", publicado na edição de março de 1998 de Actes de la recherche en sciences sociales.

RF: Num dos seus últimos livros, Contrefeux, o senhor pretende, conforme o subtítulo da obra, apresentar uma análise capaz de "servir à resistência contra a invasão neoliberal". Alguns dos seus críticos, entre os quais Olivier Mongin e Jeannine Verdoux-Leroux, acusam-no de populismo e de demagogia. Qual a sua aposta: a construção de uma sociedade comunista ou um novo investimento no Welfare state?

Bourdieu: Acho que o senhor leu 
demais as "críticas" que me são dirigidas de todos os lados, as quais não se tornam mais verdadeiras pelo simples fato de ser incansavelmente repetidas pelos intelectuais jornalistas e pelos jornalistas intelectuais que passam mais tempo a ler uns aos outros do que a ler os autores dos quais devem falar. Marxismo, leninismo, estruturo-marxismo, quanto ao aspecto teórico, são algumas dessas tantas "correntes de pensamento" das quais nunca parei de me dissociar, oralmente ou por escrito, em especial no tempo em que delas se reclamavam muitos dos que hoje me colam etiquetas. $\mathrm{O}$ mesmo vale para populismo, irrealismo, utopismo, quanto ao aspecto político.

Eu poderia retomar cada uma dessas acusações - pois se está em plena lógica do processo, mesmo se cada um se justifica com a necessidade de processar o suposto procurador - e mostrar que já disse e escrevi explicitamente, inúmeras vezes, o contrário. É o caso, por exemplo, da acusação de populismo, repetida à exaustão por constituir, devido às suas conotações encober-

tas, o estigma mais infamante - esquerda vermelha e esquerda parda, Partido comunista e Front National, Lênin e Céline; em suma: racismo. Deixo de lado, não podendo supor que jornalistas e ensaístas tenham lido as análises críticas do populismo que desenvolvi longamente nas Meditações pascalianas. Ou então bastaria retomar o texto, transcrito em Contre-feux, do discurso que pronunciei na Gare de Lyon, em Paris, em dezembro de 1995, cercado de representantes de todos os movimentos sociais e de todas as associações militantes, na presença de uma massa tipicamente "popular" de grevistas, ferroviários ou outros, ou seja, numa situação particularmente favorável à demagogia populista. O final dessa intervenção é consagrado a um alerta contra a tentação do populismo e a uma exortação aos intelectuais para que protejam a autonomia necessária ao cumprimento da função específica de analistas engajados.

RF: Crítico do marxismo simplista, que reduz o simbólico ao econômico, o senhor não poupa os profissionais da doxa de todos os gêneros. Como ser intelectual crítico e engajado, na atualidade, sem cair na demagogia ou na nostalgia do paraíso proletário?

Bourdieu: Nunca experimentei a nostalgia do paraíso proletário na terra nem aderi à utopia da sociedade comunista e não vou começar agora, depois de tantos esforços e de trabalho para descobrir as rudes realidadesudidogumundo social. Não se é obrigado a escolher entre o utopismo irresponsável e o fatalismo sociologista. Muito menos entre a expectativa do futuro radioso da sociedade comunista e a defesa das conquista do Welfare state; tampouco entre o fatalismo marxista e o fatalismo neoliberal; nem entre a defesa de fato arcaica do Estado nacional e o sonho, realmente fantástico, do Estado mundial. Todas essas alternativas, nas quais se tenta aprisionar qualquer projeto nuançado e construtivo, não passam de maneiras de justificar como inevitável a adesão ao statu quo neoliberal, o que se poderia chamar de laisser-faire do laisser-faire.

RF: $O$ senhor denuncia de forma arrasadora o trabalho da mídia para impor a inexorabilidade da globalização e sonha com um Estado mundial capaz de enfrentar o universo do mercado. Como realizar essa utopia?

Bourdieu: Em verdade, apesar do que dizem os fatalistas da liberdade, existe lugar para um utopismo razoável, protegido pelo conhecimento da coerção e das contradições sociais fornecido pelas ciências 
sociais. Teria de repetir aqui tudo o que disse a respeito da economia do bem-estar e, mais precisamente, do que poderia ser um Estado europeu e do que ele deveria fazer para contrapor-se à lógica infernal dos mercados financeiros e à tirania dos bancos e dos banqueiros que favorecem a criação, tanto pelo laisser-faire quanto por suas intervenções, das pressões do mercado que pretendem nos impor sob alegação de que se impõem a eles. Observo, de passagem, que os mesmos que, há alguns meses, denunciavam com violência os meus sinais de alerta contra o neoliberalismo e as minhas incitações à criação de um Estado europeu, converteram-se repentinamente, diante do desabamento da economia russa e das ameaças representadas por isso à ordem neoliberal, às necessidades de regulação estatal.

RF: A mão esquerda do Estado, de acordo com a sua expressão, pode realmente enfrentar a mão direita sem recorrer a uma perspectiva revolucionária considerada ultrapassada mesmo por muitos dos antigos partidos comunistas?

Bourdieu: O utopismo razoável deve alimentar-se do conhecimento das tendências para se contrapor a elas. Por exemplo, as que conduzem as sociedades mais avançadas do Estado social ao Estado penal nada têm de fatalidade ou de inexorabilidade; inscrevem-se numa política econômica baseada na ignorância ativa dos custos econômicos e sociais das "economias" - no sentido da não-despesa - econômicas. Em resumo, o dinheiro que não é destinado para as escolas ou creches, será, cedo ou tarde, para as prisões.

RF: Intelectual, pesquisador e militante, o senhor combate em favor dos sem-documentos e de todos os excluídos da sociedade francesa. Com a conquista da Copa do Mundo, falou-se muito numa vitória da França miscigenada. Estaria o esporte ajudando a enfrentar a atração pela extrema direita encarnada no Front National de Le Pen?

Bourdieu: Não estou seguro que se possa conceder ao esporte espetáculo a capacidade de integrar, mesmo simbolicamente, uma sociedade ameaçada pela segregação. Creio, ao contrário, que a prática do esporte, em particular a do futebol, nos pequenos clubes amadores, preenchia, e continua a fazê-lo, mas cada vez com mais dificuldade, essa função de integração, especialmente pela oferta de uma via de ascensão social de substituição aos que, na falta de capital cultural herdado, não estão capacitados para tomar a via real proposta pela escola. Mas, conforme mostrei num trabalho recente, a submissão crescente do esporte à lógica do comércio, através da comercialização do espetáculo esportivo televisionado, tende a cortar a ligação orgânica entre o esporte de alto nível e a prática esportiva de base; ou, de maneira mais precisa, no caso do futebol, entre os grandes clubes profissionais, cada vez mais transformados em empresas capitalistas, por vezes cotadas em bolsa, e os pequenos clubes amadores, direcionados para objetivos pedagógicos e sustentados em grande parte por uma devoção militante. Assim, o verdadeiro percurso que poderia conduzir o garoto das favelas ou das banlieues, desde a pequena equipe local ou da escolinha de futebol do clube grande, até a equipe nacional e a carreira internacional, está cada vez mais ameaçado, tanto na realidade quanto nas representações.

Dito isso, o esporte é, junto com a escola, um dos terrenos onde as tentações racistas e xenófobas encorajadas pelo Front National podem ser combatidas de maneira eficaz. Seria preciso falar também dos mecanismos que favorecem o racismo, e o sexismo, no mundo do trabalho, e dos meios eficazes para combatê-los.

RF: Com Sobre a televisão, o senhor desmantelou a lógica da mídia baseada na mercadoria, na circularidade dos temas, nos convidados intercambiáveis, na conivência, na troca de favores no domínio literário. O mundo cultural é uma farsa onde os primeiros enganados são os consumidores, mais ou menos intelectualizados, de obras de alguns autores de referência criados pelo marketing das editoras em associação com a imprensa?

Bourdieu: A análise crítica do papel 
da televisão é um elemento capital da luta contra a imposição da visão dominante do mundo social e do seu devir. O mais importante consiste na influência que a televisão exerce sobre a totalidade do jornalismo e, através dele, sobre o conjunto da produção cultural. A lógica do comércio, simbolizada pelos índices de audiência, do sucesso comercial, da venda e do marketing, como meio específico para atingir esses fins puramente temporais, impôs-se aos poucos; em certos casos, através das editoras e dos produtores estreitamente associados à imprensa, como os filósofos e os escritores da mídia aos quais me referia; mas também através de outras vias. Essa lógica se impôs em primeiro lugar ao campo filosófico, com os "novos filósofos", e ao campo literário, com os grandes best-sellers internacionais e o que Pascale Casanova chamou de world fiction, ou seja, em especial os romances acadêmicos à David Lodge ou Umberto Eco; mas ela atingiu também o campo jurídico, com os processos sensacionalistas arbitrados pela mídia, e no próprio campo científico, com a intrusão da notoriedade jornalística na avaliação dos cientistas e das suas obras. Para o aprofundamento da questão, só posso remeter ao meu livro Sobre a televisão, no qual descrevo todos esses processos, e sobretudo ao número especial de Actes em que diversos pesquisadores, entre os quais Patrick Champagne e Rémi Lenoir, analisaram o efeito da influência ou da dominação da televisão em diferentes campos.

RF: Em As Regras da arte, o senhor mostrou que não basta a obra para impor um autor; é preciso também um contexto favorável. Não existe sucesso sem um capital social prévio. Atualmente as editoras preferem publicar obras mediocres de personalidades da mídia, detentoras de capital seguro, pois a imprensa não vacilará em promover os seus representantes. $O$ imaginário da mídia está anexando a literatura e as ciências humanas em nome da "clareza", da suposta vontade do consumidor e da rejeição à "chatice"?

Bourdieu: Tudo isso corresponde a um dos efeitos, num campo particular, da invasão da televisão e da visão da mídia. De fato, vê-se cada vez mais o desenvolvimento de uma produção "média", no duplo sentido de intermediário e também de medíocre, entre a má ciência e o mau jornalismo, e não, como a boa vulgarização, entre os sábios e os que desejam aprender. Os editores, guiados pelo interesse exclusivo do sucesso comercial, associam-se a autores "da mídia", os detentores de uma notoriedade adquirida previamente na mídia: jornalistas, ensaístas, painelistas de televisão, etc. Isso para cobrir os mostradores das livrarias de obras que fazem circular os "preconceitos" e os lugares-comuns da doxa semi-erudita. Em particular, o pequeno lote de falsos problemas partilhados pelo universo político-jornalístico - Estado ou mercado, eutanásia ou obsessão terapêutica - que servem também de pretexto às dissertações dos filósofos de televisão.

O chamado "pensamento único" é menos uma temática do que uma problemática comum. A dificuldade para estabelecer a comunicação com os jornalistas concerne, em essência, para o pesquisador, à necessidade deste de não se perder na conversa fiada, de poder furar a proteção dos lugares-comuns, os tópicos e problemas generalizantes propostos, com toda inocência, pelo campo jornalístico. Dito isso, tais processos conduzem à manutenção da ameaça crescente que pesa sobre a autonomia do pensamento - científico, artístico ou qualquer outro. Quando não se tem a possibilidade de censurar pura e simplesmente o pensamento "autêntico", em nome das exigências da clareza e da simplicidade, denunciam-se, em função do caráter inutilmente enfadonho, os textos e os autores que respeitam as exigências de suas disciplinas. Esse é apenas um dos exemplos desses abusos de poder simbólicos que ameaçam a autonomia indispensável à realização da lógica específica dos diferentes campos, como a importação peremptória de critérios de julgamento não pertinentes.

RF: $O$ senhor afirma que os intelectuais devem lutar contra o "bombardeio" da mídia que fornece, a cada dia, em nome do diverti- 
mento, uma visão reducionista das realidades sociais, como a fábula da "princesa do povo". De que maneira os intelectuais, excluídos da mídia, podem combater a lógica que esta impõe?

Bourdieu: Trata-se, efetivamente, de uma questão difícil. Creio, ao contrário do sugerido pelos jornalistas que vêem uma contradição no fato de se ir à televisão quando dela se é crítico, que é possível, desejável e necessário recorrer à mídia, em certas ocasiões, com discernimento, para combater os efeitos funestos da própria mídia. Sob a condição, claro, de se estar em medida de garantir à mensagem um mínimo de eficácia; portanto de controlar, ao menos parcialmente, o processo de difusão jornalística, o que pressupõe não ter como único objetivo "aparecer na televisão", ser visto e valorizar-se. É preciso ter bastante poder para impor condições. Estas duas últimas coisas estão em parte ligadas. Foi por isso que Kundera, em conseqüência de diferentes desventuras com jornalistas, decidiu não conceder mais entrevistas, ou somente por escrito e a partir de questões realmente pertinentes para ele. Mas o que se admite ao escritor, em nome do direito à forma, dificilmente se concederá ao historiador ou ao sociólogo, em relação aos quais cada um se sente no direito de copidescá-los de maneira mais ou menos livre.

RF: O estudo da economia das trocas simbólicas é uma das suas marcas. Com A Distinção, o senhor desmascarou todo um universo entregue às ilusões da objetividade do gosto e às ideologias do universalismo útil aos esquemas de dominação social. Não the parece que certas "vanguardas" e intelectuais da moda utilizam a sua obra para simular uma consciência e afirmar-se ainda mais pela apropriação da "cultura necessária" para se impor socialmente? Em resumo: a leitura de Pierre Bourdieu como signo de distinção social?

Bourdieu: Não há, sem dúvida, quase nada que não possa funcionar como signo de distinção social, voluntária ou involuntariamente. Não vejo por que meu livro, A Distinção, seria uma exceção. Existe numa cidade alemã, não sei mais em qual, uma loja da moda chamada Habitus...

RF: Seus "livrinhos", rejeitados ou combatidos pela mídia, vendem-se aos milhares de exemplar. No último, o senhor se volta para $A$ Dominação masculina e mostra-se grande admirador de Virginia Woolf. A arte é mais poderosa do que a sociologia para dar conta do vivido?

Bourdieu: Acontece, de fato, de os escritores captarem, por suas próprias vias, coisas que escapam mesmo à análise sociológica mais fina. Tentei demonstrar isso nos casos de Flaubert, de Faulkner ou mesmo de Mallarmé, o qual viu muito bem o segredo mais bem guardado do campo literário, ao mesmo tempo que o protegeu da divulgação profanadora, "ímpia", através do esoterismo da expressão. O mesmo vale para muitos outros. Seria preciso analisar a diferença muito profunda que separa a manifestação literária da descoberta científica.

RF: Em A Dominação masculina, o senhor diz que quase o mesmo comportamento - sorrir, baixar os olhos, aceitar as interrupções - é exigido das mulheres cabilas e das americanas ou européias. O feminismo não mudou realmente o Ocidente nos últimos 30 ou 40 anos como pensam muitos intelectuais, inclusive a historiadora Michelle Perrot?

Bourdieu: Por que simplificar a esse ponto o que eu disse? As coisas, evidentemente, mudaram, sob o efeito de diferentes fatores, dentre os quais o mais importante certamente não é, sem dúvida, o feminismo, mas antes certas contradições do sistema escolar - especialmente nas suas relações com o mundo do trabalho - do qual o próprio feminismo é, com certeza, por um lado, a expressão. Certas coisas realmente fundamentais, nas estruturas sociais e nas estruturas cognitivas, perpetuaram-se, sob uma forma idêntica ou transformada. Por exemplo, a oposição entre o duro e o mole, o seco e o úmido, central na cosmologia mediterrânea, encontra-se no seio do mundo universitário ou mesmo científico sob a forma da dicotomia entre as disciplinas literárias e as científicas; estas, consideradas hard, muito em especial a matemática, sendo 
tidas por "ressecantes" e pouco adequadas para as mulheres, fadadas ao soft. Muitas coisas mudaram mas, sem dúvida, não tanto quando se possa crer tomando por base indicativos superficiais, não necessariamente relativos aos pontos mais importantes. Além disso, as diferenças deslocaram-se e a distância tende a mantê-las como numa corrida de obstáculos. Tanto é assim que os trabalhos de historiadores como Michelle Perrot, por quem tenho a maior estima, sobre a história das mulheres, revelam a questão das condições históricas da des-historização da diferença, através da história - no sentido de produto da história e não da natureza - entre os gêneros.

RF: Mais uma vez, no caso, o senhor mostra a lógica da distinção, com a recusa da vulgaridade das microssaias ou dos decotes demasiado generosos, como uma forma de impor um modelo de comportamento. No seu entender, a saia preenche uma função semelhante à da batina dos padres. O corpo das mulheres continua, apesar do discurso da liberação, a ser adestrado para aceitar a dominação masculina?

Bourdieu: $O$ que denominamos de "feminilidade" é o produto de um adestramento permanente do corpo e das incessantes chamadas à ordem, entre os quais o mais importante, por ser inerte e reificado, é a vestimenta. Seria preciso construir ou ler a história da roupa feminina, desde as formas caricaturais mais complicadas, a ponto de impedirem ou tornar difíceis os deslocamentos elementares, até as mais simples, como uma história do adestramento do corpo feminino, tratando-a como um capítulo da história da educação.

RF: Ao citar Lucien Bianco, "as armas do fraco sempre são armas fracas", o senhor refuta qualquer idéia de dominação do homem pela mulher através da sedução ou de qualquer outro artifício "feminino". A originalidade do seu novo trabalho encontra-se no combate a esse tipo de noção cada vez mais em voga?

Bourdieu: As astúcias da razão masculina são inumeráveis e bem que eu gostaria de ter analisado todas as razões e as racionalizações de que se arma o "machis- mo", neo ou paleo, para legitimar-se. Apresentei, parece-me, os princípios de uma análise da sedução capaz de ser, ao mesmo tempo, realmente compreensiva e objetiva na descrição da injunção em forma de double bind continuamente dirigida à mulher: seja aberta e fechada, ofereça-se e recusese, seja acessível e inacessível, prometida e proibida.

RF: As mulheres continuam, conforme a sua análise, a ser dominadas em casa e no trabalho. A virilidade dos homens persiste como o signo de uma superioridade sempre em busca de reprodução. A descoberta do Viagra representa um convite aos prazeres do sexo ou um novo instrumento de confirmação da potência, ainda que artificial, masculina?

Bourdieu: Em princípio, baseado no conhecimento que tenho do uso de afrodisíacos nas sociedades masculinas, tendo a pensar que o Viagra poderia ter como função, sobretudo, suspender a ansiedade ligada à necessidade de afirmar a qualquer preço a virilidade e através disso a superioridade masculina. Mas é, sem dúvida, muito mais complicado do que isso e somente uma análise estatística permitiria descrever, em toda a sua complexidade e diversidade. os usos sociais desse gadget fisiológico.

RF: Adversário da Europa do capital, o senhor pensa em ser candidato nas próximas eleições européias? Por qual partido?

Bourdieu - Se o senhor leu e entendeu o que nunca parei de dizer e de escrever a respeito da necessária autonomia dos intelectuais, deve saber que essa questão não faz sentido.

RF: Nada lhe escapa: educação, mídia, mecanismos de distinção social, a miséria mundial, as elites, as relações entre homens e mulheres, o mito do amor romântico, as regras da arte. $O$ intelectual deve caracterizar-se pela rejeição às zonas de sombra e pela busca, contra tudo e todos, das Luzes?

Bourdieu: Sim, creio nas luzes, mas a nova Aufklärung, que tem a minha admiração, só pode realmente esclarecer se ilumina a si mesma. Quero dizer com isso que a razão argumentativa, capaz de nada dei- 
xar na sombra, deve ser também capaz de voltar para si mesma a sua lucidez crítica e de compreender que um certo racionalismo pode, por vezes, ser fator de obscurantismo

\section{Nota}

Esta entrevista foi publicada em parte no Caderno Mais da Folha de São Paulo de 07/02/1999 